\title{
O dilema do editor de uma revista biomédica: aceitar ou não aceitar
}

\section{Lewis Joel Greene}

\section{Resumo}

Esta palestra trata do processo de avaliação de artigos científicos para publicação na área biomédica, levantando pontos como integridade da literatura científica, qualidade dos dados, relevância da pesquisa etc. Descreve a experiência do Brazilian Journal of Medical and Biological Research na avaliação da literatura científica.

\section{Palavras-chave}

Avaliação de artigos científicos; Processo editorial de periódicos científicos;

Periódicos científicos.
Primeiro, quero agradecer a Abel Packer e a Rogério Meneghini, não só pelo convite, mas pela sua força em relação ao Projeto SciELO - Scientific Electronic Library Online. Como presidente da Associação Brasileira de Editores Científicos (Abec), posso afirmar, em nome da diretoria, que esse projeto é a mais importante novidade dos últimos cinco ou dez anos. Parabéns. Nós esperamos que o projeto continue.

Desejo discutir, na qualidade de editor de uma revista da área biomédica, como nós avaliamos trabalhos com vistas à publicação. Primeiro, quero lembrar de coisas muito óbvias, mas que são importantes. A integridade da literatura científica é absolutamente necessária para o desenvolvimento da ciência. Se nossa literatura e nossas revistas não tiverem integridade, não poderemos fazer ciência. Então, essa é uma função primária de todos nós, que temos interesse nas revistas e na disseminação da informação científica. Estamos usando o conceito de ciência de uma forma mais aberta, incluindo as áreas de humanas e outras áreas de especialização que não são ciência por definição tradicional.

As funções de uma revista em todo o mundo, geralmente, podem ser resumidas como memória da ciência e como meio de divulgação de resultados de pesquisa para a comunidade científica e para a sociedade. Além disso, a revista pode fornecer parâmetros para a avaliação da produção científica dos pesquisadores e das instituições.

* Trabalho apresentado no Seminário sobre Avaliação da Produção Científica, realizado em São Paulo pelo Projeto SciELO, de 4 a 6 de março de 1998.
Entretanto, as revistas de países em desenvolvimento têm atribuições e funções adicionais, que não devemos esquecer. As revistas podem e devem estabelecer e implementar critérios de qualidade para a realização e a divulgação da pesquisa. Eu e meus colegas do Brazilian Journal of Medical and Biological Research (BJMBR) consideramos esse aspecto didático da revista muito importante. As revistas podem ajudar a consolidar áreas de pesquisa, além de treinar revisores e autores por meio das análises dos trabalhos. São essas análises que permitem o desenvolvimento do senso crítico, atuando na formação de autores e revisores.

Trio necessário para a avaliação da ciência são os autores, revisores e editores. O editor é responsável pela manutenção da qualidade científica e editorial da revista. Isso é muito vago, mas essa é a responsabilidade de um editor ou de um grupo de editores. A obrigação principal de um editor é garantir que os manuscritos submetidos para publicação sejam avaliados de forma apropriada: objetivamente, sem brigas e sem preconceitos. O editor não deve escolher revisores visando a resultados previsíveis. De fato, o editor é um tipo de ombudsman, que deve tentar proteger os direitos dos autores e dos revisores, contribuindo para a comunicação entre eles.

Quero discutir minha experiência como editor do BJMBR. Há 18 anos, quando a revista tinha periodicidade trimestral, publicavam-se 40 trabalhos por ano. Hoje, com periodicidade mensal, a revista publica entre 200 e 250 trabalhos por ano, acompanhados de mais ou menos mil pareceres. A revista tem uma tiragem de 2 mil cópias e é distribuída para membros e bibliotecas. Seu fator de impacto nos últimos 18 anos tem 
estado entre 0,3 e 0,5 , o que, provavelmente, está abaixo da média para o Science Citation Index, mas bem acima da maioria das revistas da América Latina. Entretanto, em 1996, a revista alcançou a marca de 700 citações no Science Citation Index.

O BJMBR tem uma organização composta por três editores, uma editora executiva e sete editores seccionais. Importante salientar que todos esses editores estão produzindo ciência ativamente. Está implícito que só pesquisadores produtivos têm habilidade para avaliar e indicar outros para emitirem pareceres. No BJMBR, não usamos os pareceres simplesmente como votos, mas atentamos para o seu conteúdo, que deve ser analítico e detalhado.

Cada revista tem uma personalidade. $\mathrm{O}$ BJMBR não pretende ser simplesmente um repositório de dados, e sim estimular novos dados, novas abordagens e novos conceitos. Publicamos Artigos Completos, Comunicações Breves, Artigos de Revisão, que devem ser analíticos e críticos, além de uma seção chamada Concepts and Comments. As Comunicações Breves são simplesmente trabalhos curtos (duas tabelas, duas figuras ou uma de cada) que não são somente resultados preliminares.

Artigos de Revisão são uma arma muito potente. Um bom artigo, analítico e crítico será bom para a revista, aumentando o número de citações por outros. Além disso, para o pesquisador, representa uma oportunidade de sintetizar sua visão em um trabalho crítico e objetivo. Para escrever artigos de revisão, convidamos os melhores grupos, os mais maduros.

O processo de avaliação do trabalho científico tem dois aspectos: estrutural e de conteúdo (qualidade). No caso do BJMBR, no processo de avaliação usase um formulário adequado com perguntas que servirão como orientação para verificar inicialmente a originalidade e a importância da contribuição. A seguir, enfoca-se a relevância da metodologia, os resultados e a discussão, e até mesmo a relevância das figuras e tabelas. Solicita-se uma recomendação, mas lembramos que uma recomendação sem uma análise do trabalho não é aceitável: "o trabalho é bom, aceite-se"; ou "o trabalho é ruim, rejeite-se". Isso não é um parecer. Os assessores indicados pelo editor seccional emitem seus pareceres, e o conjunto de dois ou três pareceres é centralizado na sede da revista e enviado para a decisão do editor seccional. Em geral, as decisões do editor de seção são homologadas pelos editores-chefes. As seções da revista correspondem a áreas bem diferentes entre si, e cada uma delas tem independência para sua atuação.

Dados relativos a 1996, abrangendo sete áreas diferentes, mostram que temos $12 \%$ de trabalhos rejeitados e $22 \%$ de trabalhos arquivados. Em 1997, esses números estão entre $21 \%$ e $18 \%$. Temos, então, um controle de qualidade que é feito pelos editores de seção e por pesquisadores especialistas da área. Todos os processos são analisados pelos editores, que resolvem eventuais problemas. Avaliar um manuscrito quanto à sua objetividade e originalidade não é fácil, a não ser que seja muito bom ou muito ruim. O problema está entre os extremos.

É preciso, também, verificar se a metodologia utilizada foi apropriada para responder às questões propostas. Quando um método não apropriado é utilizado, não se faz ciência. Os dados experimentais possuem qualidade suficiente para serem interpretados em contextos objetivos? Os resultados justificam as conclusões indicadas pelo autor? Geralmente, nos trabalhos originais, deve-se insistir para que os autores se aproximem mais dos resultados, sem fazer grandes extrapolações. Voltando para a definição dos objetivos da pesquisa, o revisor deve perguntar se os resultados e as conclusões são relevantes diante de outras questões importantes estudadas por outros investigadores.

Método apropriado e state-of-the-art também são considerações problemáticas. Em minha área, que é bioquímica estrutural, se quero publicar em revistas de primeira linha, preciso ter dados fornecidos por um espectrômetro de massa para demonstrar o peso molecular e a homogeneidade da matéria. No Brasil, temos apenas dois aparelhos que podem fazer isso e, para que eu possa publicar em boas revistas, preciso fazê-lo por meio da colaboração com outros laboratórios. No entanto, como editor, quando preciso decidir para - Brazilian Journal, muitas vezes aceitamos documentação que não chega a ser do tipo state-of-the-art exigida por revistas de primeira linha.

A qualidade de dados passa, também, pelas palavras sugerir, indicar, demonstrar, provar. Os autores gostam de misturar palavras desse tipo. As interpretações devem ser restritas ou amplas? Relevância? Prioridade? São questões problemáticas.

As características de um manuscrito de qualidade precária são as seguintes: experimentos não logicamente ligados, dados não analisados, coleções de dados sem conclusões, discussão que vai muito além dos resultados, relevância questionável em termos de questões atuais, repetições e, finalmente, o fator fundamental para um documento científico, a forma em que está redigido. No BJMBR, exigimos o domínio da língua e verificamos todos os trabalhos quanto ao uso do inglês. Fazemos também sugestões para as figuras e tabelas para que sejam mais efetivas; $\mathrm{e}$ refazemos coisas, já que nossos clientes não têm muita experiência no marketing de seus produtos.

O parecer do editor de uma revista internacional pode descrever um manuscrito com as seguintes considerações: apesar de o trabalho estar bem redigido, de os objetivos serem claros e relevantes, os métodos serem adequados, a análise dos dados estar correta etc., o trabalho não pode ser aceito para publicação por estar classificado como "baixa prioridade". Esse problema, que se refere ao custo de páginas publicadas, existe nas revistas internacionais e está começando a atingir o BJMBR.

O que quero demonstrar é que existe subjetividade na editoração e nas decisões quanto a trabalhos individuais, embora existam coisas concretas e objetivas que podem ser avaliadas. $\mathrm{O}$ impacto da revista depende desse tipo de decisões objetivas e subjetivas do editor. É isso que dá personalidade à revista. 
The dilemma of the editor of a biomedical journal: to accept or not to accept

\section{Abstract}

This lecture discusses the evaluation process of scientific articles submitted for publication in the biomedical area, pointing to issues such as integrity of the scientific literature, quality of data, relevance of the research etc. It also describes the Brazilian Journal of Medical and Biological Research experience in the scientific literature evaluation.

\section{Keywords}

Scientific articles evaluation; Editorial process of scientific periodicals; Scientific periodicals.

\section{Lewis Joel Greene}

Presidente da Associação Brasileira de Editores Científicos e editor do Brazilian Journal of Medical and Biological Research.

bjournal@fmrp.usp.br 